\title{
Retraction Note to: Application of ultra-high performance concrete wet joint technology in marine environment
}

\author{
Zhaofeng $\mathrm{Liu}^{1} \cdot \mathrm{Bin} \mathrm{Du}^{2} \cdot$ Huadong $\mathrm{Zhu}^{3}$
}

Published online: 13 December 2021

C) Saudi Society for Geosciences 2021

Retraction Note to: Arabian Journal of Geosciences (2021) 14: 1608

https://doi.org/10.1007/s12517-021-07836-3

The Editor-in-Chief and the Publisher have retracted this article because the content of this article is nonsensical. The peer review process was not carried out in accordance with the Publisher's peer review policy. Authors Bin Du and Huadong Zhu have not responded to correspondence regarding this retraction. The Publisher has not been able to obtain a current email address for author Zhaofeng Liu.

The original article can be found online at https://doi.org/10.1007/ s12517-021-07836-3.

Huadong Zhu

zhdskjc@163.com

1 School of Building Engineering, Hunan Institute of Engineering, Xiangtan 411104, Hunan, China

2 College of Civil Engineering, Guizhou University, Guiyang 550025, Guizhou, China

3 Guizhou Shunkang Testting Co., Ltd, Guiyang 550000, Guizhou, China 